Keywords: bladder cancer; hyaluronic acid; epithelial-mesenchymal transition; 4-methylumbelliferone; biomarker; targeted treatment

\title{
Hyaluronic acid family in bladder cancer: potential prognostic biomarkers and therapeutic targets
}

Daley S Morera ${ }^{1,11}$, Martin S Hennig ${ }^{2,11}$, Asif Talukder ${ }^{3}$, Soum D Lokeshwar ${ }^{4}$, Jiaojiao Wang ${ }^{1}$, Michael Garcia-Roig ${ }^{5,12}$, Nicolas Ortiz ${ }^{5,13}$, Travis J Yates ${ }^{6,14}$, Luis E Lopez ${ }^{1}$, Georgios Kallifatidis ${ }^{7}$, Mario W Kramer $^{2}$, Andre R Jordan ${ }^{1,6}$, Axel S Merseburger ${ }^{2}$, Murugesan Manoharan ${ }^{8}$, Mark S Soloway ${ }^{9}$, Martha K Terris $^{10}$ and Vinata B Lokeshwar ${ }^{*}, 1$

${ }^{1}$ Department of Biochemistry and Molecular Biology, Medical College of Georgia, Augusta University, 1410 Laney Walker Boulevard, Room CN 1177A, Augusta, GA 30912-2100, USA; 'Department of Urology, University Hospital Schleswig-Holstein, Kiel, Lübeck 23538, Germany; ${ }^{3}$ Department of Surgery, Medical College of Georgia, Augusta University, Augusta, GA 30912, USA; ${ }^{4}$ Honors Program in Medical Education, University of Miami-Miller School of Medicine, 1600 NW 10th Avenue, Miami, FL 33136, USA; ${ }^{5}$ Department of Urology, University of Miami-Miller School of Medicine, 1600 NW 10th Avenue, Miami, FL 33136, USA; ${ }^{6}$ Sheila and David Fuente Graduate Program in Cancer Biology, Sylvester Comprehensive Cancer Center, University of MiamiMiller School of Medicine, 1600 NW 10th Avenue, Miami, FL 33136, USA; ${ }^{7}$ Georgia Cancer Center, Medical College of Georgia, Augusta University, Augusta, GA 30912, USA; ${ }^{8}$ Miami Cancer Institute, Baptist Health South Florida, 8900 N Kendall, Miami, FL 33176, USA; ${ }^{9}$ Memorial Healthcare System, 20801 Biscayne Blvd Ste 203, Aventura, FL 33180, USA and ${ }^{10}$ Department of Surgery, Division of Urology, Medical College of Georgia, Augusta University, Augusta, GA 30912, USA

Background: Molecular markers of clinical outcome may aid in designing targeted treatments for bladder cancer. However, only a few bladder cancer biomarkers have been examined as therapeutic targets.

Methods: Data from The Cancer Genome Atlas (TCGA) and bladder specimens were evaluated to determine the biomarker potential of the hyaluronic acid (HA) family of molecules - HA synthases, HA receptors and hyaluronidase. The therapeutic efficacy of 4-methylumbelliferone (4MU), a HA synthesis inhibitor, was evaluated in vitro and in xenograft models.

Results: In clinical specimens and TCGA data sets, HA synthases and hyaluronidase-1 levels significantly predicted metastasis and poor survival. 4-Methylumbelliferone inhibited proliferation and motility/invasion and induced apoptosis in bladder cancer cells. Oral administration of $4 \mathrm{MU}$ both prevented and inhibited tumour growth, without dose-related toxicity. Effects of $4 \mathrm{MU}$ were mediated through the inhibition of CD44/RHAMM and phosphatidylinositol 3-kinase/AKT axis, and of epithelial-mesenchymal transition determinants. These were attenuated by HA, suggesting that $4 \mathrm{MU}$ targets oncogenic HA signalling. In tumour specimens and the TCGA data set, HA family expression correlated positively with $\beta$-catenin, Twist and Snail expression, but negatively with E-cadherin expression.

Conclusions: This study demonstrates that the HA family can be exploited for developing a biomarker-driven, targeted treatment for bladder cancer, and $4 \mathrm{MU}$, a non-toxic oral HA synthesis inhibitor, is one such candidate.

\footnotetext{
*Correspondence: Dr VB Lokeshwar; E-mail: vlokeshwar@augusta.edu

${ }^{11}$ These authors contributed equally to this work and are joint first authors.

${ }^{12}$ Current Address: Georgia Pediatric Urology, Children's Healthcare of Atlanta, Emory University, Atlanta, GA, USA.

${ }^{13}$ Current Address: Womack Army Medical Center, Fort Bragg, NC, USA.

${ }^{14}$ Present Address: Department of Cancer Biology, University of Pennsylvania, Philadelphia, PA, USA.
}

Received 6 June 2017; revised 4 August 2017; accepted 18 August 2017; published online 3 October 2017

(C) 2017 Cancer Research UK. All rights reserved 0007-0920/17 
The divergent molecular pathways of low- and high-grade tumour development, heterogeneity in tumour progression and frequent recurrence are a few of the unique features of bladder cancer (BCa) that contribute to the challenges and high cost associated with its clinical management (Leal et al, 2016). The relative ease of urinebased tests has led to the discovery of potential BCa biomarkers. However, the functional links of many of these biomarkers to $\mathrm{BCa}$ growth and progression remain unknown. Furthermore, very few of these biomarkers have been targeted for therapy (SchmitzDrager et al, 2015; Leal et al, 2016; Nagata et al, 2016). Our previous studies have demonstrated that hyaluronic acid (HA) family members are potentially accurate biomarkers for $\mathrm{BCa}$ diagnosis, as well as for predicting disease recurrence and progression (Lokeshwar et al, 2000; Kramer et al, 2010, 2011).

Hyaluronic acid is a non-sulphated glycosaminoglycan. Hyaluronic acid and HA family members - HA synthases (i.e., HAS1, HAS2, HAS3), HA receptors (i.e. CD44, RHAMM) and the tumour-derived hyaluronidase HYAL-1 - promote tumour growth, metastasis and angiogenesis (Jordan et al, 2015; Karousou et al, 2016; Turley et al, 2016). These HA family members have shown the potential to be diagnostic and/or prognostic biomarkers in a few malignancies (Lokeshwar et al, 2000, 2002; Ekici et al, 2004; Golshani et al, 2007, 2008; Gomez et al, 2009; Chi et al, 2012; Peng et al, 2016). We have previously shown that urinary HA levels detect $\mathrm{BCa}$ with $>85 \%$ accuracy (Lokeshwar et al, 1997, 2000, 2002). As a combined marker, elevated HAS2 and HYAL-1 mRNA levels detect BCa with $\sim 82 \%$ accuracy (Kramer et al, 2011). In BCa tissues, HA is synthesised by tumour stroma and tumour cells (Hautmann et al, 2001; Lokeshwar et al, 2001). Owing to HYAL-1 activity, pericellular HA in tissues and patients' urine consists of both high molecular mass and small HA fragments; some of these HA fragments are angiogenic (Lokeshwar et al, 1997, 2001). In preclinical models, while HA synthases and/or HYAL-1 expression enhances tumour growth, angiogenesis and metastasis, their downregulation suppresses these tumour phenotypes (Lokeshwar et al, 2005a, b; Golshani et al, 2008; McAtee et al, 2014). Interestingly, HAS2 is a target of the glycogen debranching enzyme AGL, a tumour suppressor. HAS2 upregulation due to AGL downregulation promotes BCa growth (Guin et al, 2016). Pericellular HA-HA receptor interaction stimulates tumour cell functions by inducing oncogenic signalling, including the phosphatidylinositol 3-kinase (PI3-K)-AKT pathway and the epithelial-mesenchymal transition (EMT). Epithelial-mesenchymal transition markers such as Twist may have the potential in $\mathrm{BCa}$ diagnosis and predicting its progression or recurrence (Fantony et al, 2015; Singh et al, 2016). However, the correlation between HA family and EMT marker expression has not been examined.

Since tumour-associated HA promotes tumour growth and progression, and $\mathrm{BCa}$ cells express more than one HA synthase, inhibition of HA synthesis by a small molecule may be a better treatment approach for controlling $\mathrm{BCa}$ than targeting individual HA synthases. 4-Methylumbelliferone (4MU; 7-hydroxy-4-methylcoumerin or hymecromone) is a HA synthesis inhibitor. 4-Methylumbelliferone is sold as a supplement in Europe and Asia to improve liver health. 4-Methylumbelliferone is not associated with any toxicity and has a maximum tolerated dose in mice of $2.8-7.3 \mathrm{~g} \mathrm{~kg}^{-1}$ (National Institute for Occupational Safety; RETCs No. GN7000000). The two building blocks of HA synthesis are UDP-glucuronic acid and $N$-acetyl-D-glucosamine. Uridine 5'-diphospho-glucuronosyltransferase-glucuronic acid is a substrate of UDP-glucuronyltransferases (Nakamura et al, 1997; Kakizaki et al, 2002, 2004). In mammalian cells exposed to 4MU, UDP-glucuronyltransferase causes glucuronidation of $4 \mathrm{MU}$, which depletes the intracellular UDP-glucuronic acid pool, inhibiting HA synthesis (Nakamura et al, 1997; Kakizaki et al, 2002, 2004). Since the $K_{\mathrm{m}}$ values of UDP-glucuronyltransferases and HA-synthases range between 0.1 and $0.9 \mathrm{~mm}$, the $\mathrm{IC}_{50}$ of $4 \mathrm{MU}$ for inhibiting $\mathrm{HA}$ synthesis is $\sim 0.4 \mathrm{~mm}$ (Nakamura et al, 1997; Kakizaki et al, 2002, 2004; Lokeshwar et al, 2010; Yates et al, 2015). In addition, 4MU downregulates the expression of HA synthases and UDPdehydrogenase, which are key enzymes in HA synthesis (Kultti et al, 2009; Saito et al, 2013). In tumour models, 4MU has shown antitumour activity (Lokeshwar et al, 2010; Arai et al, 2011; Piccioni et al, 2012; Yates et al, 2015; Guin et al, 2016; Nagase et al, 2016; Ikuta et al, 2017). Our previous studies on preclinical models of prostate cancer demonstrated the chemopreventive and therapeutic efficacies of $4 \mathrm{MU}$ to prevent and inhibit prostate cancer development, growth, and its progression at doses comparable to those used in humans (Lokeshwar et al, 2010; Yates et al, 2015). In this study, we evaluated the expression of the HA family molecules in clinical specimens and in The Cancer Genome Atlas (TCGA) data set and targeted it for treatment using preclinical models of $\mathrm{BCa}$. Moreover, we confirmed a correlation between HA family and the effectors of (i.e., EMT markers) the oncogenic HA signalling in clinical specimens.

\section{MATERIALS AND METHODS}

Cells and reagents. BCa cell lines HT1376, J82, HT1197, T24 and UMUC-3 and immortalised normal urothelial cells SV-HUC1 were purchased from American Type Culture Collection (Manassa, VA, USA). 253J-Parent and 253J-Lung cells were provided by Dr Colin Dinney (MD Anderson Cancer Center, Houston, TX, USA). Immortalised normal bladder epithelial cell line UROtsa was provided by Dr Donald Sens (University of North Dakota, Grand Forks, ND, USA). Bladder cell lines were authenticated by Genetica DNA Laboratories Inc. (Cincinnati, OH, USA). Sodium salt of 4MU (MW: 198) was purchased from Sigma-Aldrich (Saint Louis, MO, USA); other reagents and antibodies as described before (Yates et al, 2015; Jordan et al, 2016). All experiments were conducted between passages 2 and 10 .

HA ELISA-like assay. Serum-free conditioned medium (CM) of BCa cells was subjected to HA activity ELISA-like assay, as described before (Lokeshwar et al, 1997). Hyaluronic acid levels $\left(\mathrm{ng} \mathrm{ml}^{-1}\right)$ were normalised to cell number. In some cases, CM were collected following $48 \mathrm{~h}$ treatment with $4 \mathrm{MU}(0.4 \mathrm{~mm})$.

Cell proliferation, apoptosis, motility and invasion assays. Bladder cancer and normal urothelial cells $\left(1.5 \times 10^{4}\right.$ cells per well) cultured in growth medium were exposed to $4 \mathrm{MU}(0-0.6 \mathrm{mM})$ either alone or in the presence of HA $\left(50 \mu \mathrm{g} \mathrm{ml}^{-1}\right)$ or a PI3-K inhibitor LY29400 $(0$ and $10 \mu \mathrm{M})$ for 48 to $72 \mathrm{~h}$. Following incubation, viable cells were counted (Trypan blue staining). Induction of apoptosis was examined in cells treated with 4MU for $48 \mathrm{~h}$ using the Cell Death ELISA Plus Kit (Roche Diagnostics, Indianapolis, IN, USA); results were expressed as apoptosis index (per 5000 cells) (Yates et al, 2015; Chanmee et al, 2016). Matrigel invasion and motility assays were carried out as described previously, except that $4 \mathrm{MU}$ and/or HA were added in both chambers of the Transwell. Incubation times for motility and invasion assays were 18 and $48 \mathrm{~h}$, respectively (Lokeshwar et al, 2005b, 2006, 2010; Yates et al, 2015; Jordan et al, 2016). In scratch wound assay, 253J-Lung cells were cultured in 0.1\% FBS-containing medium and treated with 4MU.The wound closure was photographed at different time intervals and analysed using the ImageJ Software (https://imagej.nih.gov/ij/). Per cent wound closure was calculated as: $\left(A_{0}-A_{\mathrm{m}}\right) / A_{0} \times 100$ (where $A_{0}$ is area at time 0 and $A_{\mathrm{m}}$ is area at time of measurement). Data are represented as mean \pm s.d. (triplicate determination).

Transient transfections, immunoblotting, ELISA and proximal ligation assays. 253J-Lung and HT1376 cells treated with 4MU (0 
or $0.4 \mathrm{~mm}$ ) for $48 \mathrm{~h}$ were subjected to immunoblotting for various proteins or to reverse transcription quantitative polymerase chain reaction (qPCR) assays for HA receptor and EMT marker transcripts, as described before (Yates et al, 2015; Jordan et al, 2016) In some cases, HA ( $\left.50 \mu \mathrm{g} \mathrm{ml}^{-1}\right)$ was added during $4 \mathrm{MU}$ incubation. 253J-Lung cells treated with $4 \mathrm{MU}$ ( 0 and $0.4 \mathrm{mM}$ ) were subjected to PI3-K activity assay using a colourimetric ELISA Kit (FACE PI3-K p85; Active Motif, Carlsbad, CA, USA) or to a PLA, using anti-PI3-K and CD44 antibodies as described before (Yates et al, 2015; Jordan et al, 2016). Alternatively, 253J-Lung cells were transiently transfected with a pcDNA3-Myr-HA-Akt1 or vector plasmid using Lipofectamine 2000 (Invitrogen, Carlsbad, CA, USA). Twenty-four hours following transfection, cells were treated with 4-MU (0 and $0.4 \mathrm{~mm}$ ) for $48 \mathrm{~h}$ and analysed (Yates et al, 2015; Jordan et al, 2016). For NF- $\kappa \mathrm{B}$ reported assay cells were transiently transfected with pNF- $\kappa$ B-luc and pGL4.74[hRluc/TK] plasmids. Eight hours following transfection, the cells were exposed to $4 \mathrm{MU}$ $(0.4 \mathrm{~mm})$. Following $16-18 \mathrm{~h}$ incubation, the firefly luciferase and Renilla luciferase activities were assayed. Results were expressed as a ratio of firefly luciferase to Renilla luciferase activities. (Jordan et al, 2016).

To quantify the levels of protein in immunoblot analysis, the blots were scanned and quantified using the ImageJ Software (https://imagej.nih.gov/ij/). For a specific protein, the intensity of the band in each sample was normalised to the corresponding intensities of $\beta$-actin, $\alpha$-tubulin and GAPDH bands; these three proteins were used as loading controls. The normalised intensities was calculated as described in Supplementary Tables 2 and 3.

Tumour xenograft. HT1376 cells $\left(2 \times 10^{6}\right.$ cells per $\left.0.1 \mathrm{ml}\right)$ were implanted subcutaneously on the dorsal flank of 5-6-week-old athymic mice $(n=15)$. When tumours reached $\geqslant 100 \mathrm{~mm}^{3}$, mice were randomly divided into three groups and orally gavaged with either vehicle ( $2 \%$ sucrose) or $4 \mathrm{MU}$ ( 200 or $400 \mathrm{mg} \mathrm{kg}^{-1}$ ) until day 35 , when the mice in the vehicle group were killed. In $4 \mathrm{MU}$ groups, tumour growth was monitored until day 50. To test the effect of $4 \mathrm{MU}$ on tumour generation, in the 253J-Lung subcutaneous model, 4MU treatment commenced on the day of tumour cell injection. Immunohistochemical localisation of microvessels, activated caspase- 3, E-cadherin, $\beta$-catenin and $\mathrm{p} \beta$-catenin(S552) was performed on HT1376 tumour specimens from vehicle and $4 \mathrm{MU}$ (400 $\mathrm{mg} \mathrm{kg}^{-1}$ ) treatment groups, as described before (Lokeshwar et al, 2005b, 2006; Yates et al, 2015). For immunohistochemistry, specimens were stained for microvessels (antiCD34 1:20 dilution), activated caspase-3 (1:50 dilution), E-cadherin (anti-E-cadherin $1: 1000), \quad \beta$-catenin $(1: 300)$ and anti-p $\beta$-catenin(S552) $(1: 300)$, using the IHC procedure described before (Lokeshwar et al, 2005b, 2006, 2010; Yates et al, 2015; Jordan et al, 2016). Microvessel density (MVD) was determined by counting microvessels, respectively, using a Nikon H550L microscope (Nikon, Melville, NY, USA) with a video screen camera, under $\times 400$ magnification.

Clinical specimens and TCGA database. Set 1: Normal bladder $(\mathrm{NBL} ; n=30)$ and bladder tumour (TBL; $n=40)$ specimens were collected at the University of Miami under the University of Miami's institutional review protocol. These specimens were transferred to Augusta University under an approved protocol.

Set 2: TCGA data set contains 407 unique BCa patients on whom HA family and EMT marker transcript levels, and overall survival status were available. Therefore, the TCGA data set marker levels were analysed only for the overall survival data; Supplementary Table 1 describes patient/specimen characteristics for both sets.

Reverse transcription qPCR. Total RNA isolated from tissues was subjected to reverse transcription qPCR using primers specific for each HA family or EMT marker transcripts and normalised to $\beta$-actin levels; primer sequences have been published before (Lokeshwar et al, 2000; Chi et al, 2012; Yates et al, 2015; Jordan et al, 2016). The primers used for the detection of Snail and Twist were specific for Twist1 and Snail1. Normalised transcript levels were calculated as $\left(1 / 2^{\Delta \mathrm{Cq}}\right) \times 100$ where $\Delta \mathrm{Cq}=\mathrm{Cq}$ (transcript $) \times$ $\mathrm{Cq}$ ( $\beta$-actin). CD44 variant primers detect all variant isoforms.

Statistical analysis. Mean \pm s.d. was computed for quantifiable parameters (e.g., cell number, apoptosis index, \% motility, \% invasion, tumour volume). Differences among vehicle/control and treatment groups were compared by one-way ANOVA followed by either unpaired $t$-test (e.g., control $v s$ treatment) or Tukey's multiple comparison test when comparing more than two groups; $P$-values were two-tailed. Statistical analysis for biomarker levels in both sets were performed as described before (Kramer et al, 2011). Differences between NBL and TBL specimens from patients who either developed $($ met + ) or did not develop (met - ) metastasis were compared using the Mann-Whitney $U$-test because the data showed a non-normal distribution: two-tailed $P$-values. In both sets, a logistic single parameter model (i.e., univariate analysis) was used to determine the association between a biomarker level and metastasis or survival. A Cox proportional hazards model (i.e., multivariate analysis) was used to determine which of the pre- and postoperative parameters or biomarkers predicted clinical outcome. Receiver operating characteristic curve was generated for each marker to determine the optimal cutoff limits based on the Youden's index. These cutoff limits were then used to stratify highand low-marker expression for generating Kaplan-Meier curves. Statistical analyses were performed using the GraphPad Prism (La Jolla, CA, USA) and JMP software (Cary, NC, USA).

\section{RESULTS}

HA family expression in bladder specimens. We have previously reported that among the seven HA family members (i.e., HAS1, HAS2, HAS3, CD44 standard form (CD44s), CD44 variant (CD44v), RHAMM and HYAL-1), HAS1, HAS2, HAS3 and HYAL-1 transcript and protein levels were significantly elevated in bladder tumour tissues (Kramer et al, 2011). Reanalysis of the expression data with updated clinical follow-up showed that HAS1 (3-fold), HAS2 (2.6-fold) and HYAL-1 (4.2-fold) transcript levels were significantly elevated in $\mathrm{BCa}$ tissues from patients who developed metastasis, when compared with those who did not. HAS3, CD44 and RHAMM transcript levels did not correlate with metastasis (data not shown). In univariate analysis, HAS1 and HYAL-1 levels significantly correlated with metastasis (Table 1). Kaplan-Meier plots showed that HAS1 and HYAL-1 levels significantly stratified BCa patients into low- and high-risk groups for developing metastasis (Figure 1A and B). Furthermore, only HYAL-1 transcript levels also correlated with disease-specific mortality (DSM; $\chi^{2}: 5.31 ; P=0.0212$ ). In multivariate analysis that included clinical, pathological parameters and biomarker levels, only HYAL- $1\left(\chi^{2}: 7.51 ; P=0.006\right)$ was an independent predictor of metastasis.

We also analysed the expression of HA family molecules in a TCGA data set consisting of $407 \mathrm{BCa}$ patients. In this data set, transcript levels of HAS2, HAS3 and HYAL-1 significantly correlated with overall survival (Table 1). Among HA receptors RHAMM (gene symbol HMMR) significantly correlated with overall survival ( $\left.\chi^{2} 4.57 ; P=0.0325\right)$. HAS1, HAS2 and HYAL-1 transcript levels stratified patients into low- and high-risk groups for survival (Supplementary Figure 1A-C); HAS3 also stratified patients into low- and high-risk groups for survival (data not shown). These results show that HA family members are potential prognostic predictors of clinical outcome in $\mathrm{BCa}$ patients. 
Table 1. Correlation between clinical outcome and HA or EMT markers in BCa specimens

\begin{tabular}{|c|c|c|c|c|c|c|}
\hline & \multicolumn{3}{|c|}{ Metastasis (set 1) } & \multicolumn{3}{|c|}{ Survival (set 2) } \\
\hline Parameter & $\chi^{2}$ & $\begin{array}{c}P \text { - } \\
\text { value }\end{array}$ & $\begin{array}{l}\text { Odds } \\
\text { ratio } \\
95 \% \mathrm{Cl}\end{array}$ & $\chi^{2}$ & $\begin{array}{c}P \text { - } \\
\text { value }\end{array}$ & $\begin{array}{c}\text { Range odds } \\
\text { ratio } \\
95 \% \mathrm{Cl}\end{array}$ \\
\hline HAS1 & 5.83 & $0.0157^{a}$ & $\begin{array}{c}1.63 ; \\
1.2-2.6\end{array}$ & 3.00 & 0.0833 & - \\
\hline HAS2 & 1.93 & 0.1649 & - & 4.68 & 0.0305 & $\begin{array}{c}3.44 \\
1.13-10.57\end{array}$ \\
\hline HAS3 & 0.74 & 0.3891 & - & 7.56 & 0.006 & $\begin{array}{c}3.97 \\
1.5-10.75\end{array}$ \\
\hline HYAL-1 & 7.58 & $0.0059^{a}$ & $\begin{array}{c}1.86 \\
1.3-3.3\end{array}$ & 5.01 & 0.0252 & $\begin{array}{c}4.4 i \\
1.2-16.1\end{array}$ \\
\hline$\beta$-Catenin & 2.65 & 0.1033 & - & 4.49 & 0.0340 & $\begin{array}{c}3.57 \\
1.1-11.82\end{array}$ \\
\hline Twist & 7.94 & $0.005^{a}$ & $\begin{array}{c}4.64 ; \\
1.9-17.1\end{array}$ & 11.49 & 0.0007 & $\begin{array}{c}5.29 \\
2.02-13.9\end{array}$ \\
\hline Snail & 3.48 & 0.0622 & - & 8.14 & 0.0043 & $\begin{array}{c}6.2 ; \\
1.77-21.7\end{array}$ \\
\hline E-cadherin & 0.26 & 0.607 & - & 1.11 & 0.292 & - \\
\hline \multicolumn{7}{|c|}{$\begin{array}{l}\text { Abbreviations: } \mathrm{BCa}=\text { bladder cancer; } \mathrm{Cl}=\text { confidence interval; } \mathrm{EMT}=\text { epithelial-mesench- } \\
\text { ymal transition; } \mathrm{HA}=\text { hyaluronic acid; } \mathrm{TCGA}=\text { The Cancer Genome Atlas. Univariate } \\
\text { analysis of } \mathrm{HA} \text {-family and EMT marker transcript levels to predict clinical outcome. } \\
\text { Transcript levels of seven } \mathrm{HA} \text { family and four EMT markers from clinical specimens in sets } 1 \\
\text { (clinical specimens) and } 2 \text { (TCGA data set) were evaluated for the prediction of metastasis or } \\
\text { survival by single parameter logistic regression analysis. Odds ratio and } 95 \% \mathrm{Cl} \text { are shown } \\
\text { for significant parameters. As noted in the text in multivariate analysis that included clinical } \\
\text { (age, gender), pathological (tumour grade, stage, concomitant carcinoma in situ, lymph node) } \\
\text { and biomarker levels, only HYAL-1 and Twist were significantly correlated with metastasis. } \\
{ }^{a} P \leq 0.05 \text {. }\end{array}$} \\
\hline
\end{tabular}

Effect of 4MU on HA synthesis and cellular functions in BCa cells. Measurement of HA levels by an HA ELISA-like assay showed that BCa cells secrete significant amounts of HA (100$1200 \mathrm{ng}$ per $10^{5}$ cells) in their conditioned media (Figure 1C). Incubation of 253J-Lung and HT1376 cells with $4 \mathrm{MU}(0.4 \mathrm{~mm}$ or $80 \mu \mathrm{g} \mathrm{ml}^{-1}$ of sodium salt of $4 \mathrm{MU}$ ) inhibited HA synthesis by $>90 \% \quad(P<0.0001$; Figure $1 \mathrm{C})$. This concentration of $4 \mathrm{MU}$ required for HA synthesis inhibition is consistent with those reported previously (Kakizaki et al, 2004; Lokeshwar et al, 2010). In cell proliferation assays, $4 \mathrm{MU}$ inhibited the growth of various $\mathrm{BCa}$ cells in a dose-dependent manner and at concentrations at which it inhibited HA synthesis; $56-60 \%$ growth inhibition was observed at $0.4 \mathrm{~mm}$ concentration (Figure 1D; $P<0.0001$ at each concentration when compared with untreated). 4-Methylumbelliferone did not significantly inhibit the growth of normal urothelial cells, UROtsa and SV-HUC1 (Supplementary Figure 2A). The growth inhibition caused by $4 \mathrm{MU}$ in $\mathrm{BCa}$ cells was due to a dose-dependent induction of apoptosis. At $0.4 \mathrm{~mm}$ concentration, $4 \mathrm{MU}$ caused a $3-4$-fold induction of apoptosis (Figure 1E; $P<0.0001$ ). The addition of HA during the incubation of 253J-Lung and HT1376 cells with $4 \mathrm{MU}$ attenuated the growth inhibitory effects of $4 \mathrm{MU}$; $58 \%$ vs $17 \%$ growth inhibition by $4 \mathrm{MU}$ in the absence or presence of HA (Figure $1 \mathrm{~F}$ ). The addition of HA prevented 4MU-induced apoptosis (data not shown).

Since HA regulates cell adhesion, migration and invasion (Jordan et al, 2015; Chanmee et al, 2016; Karousou et al, 2016) and $4 \mathrm{MU}$ inhibited HA synthesis by $\sim 90 \%$ at $0.4 \mathrm{~mm}$ concentration (Figure 1C), we examined the effect of $4 \mathrm{MU}$ on migration, chemotactic motility and invasive activity at this concentration. In these and subsequent assays, 253J-Lung and HT1376 cells were chosen, because these cells synthesise high levels of HA, and are invasive, but express different isoforms of CD44; 253J-Lung express CD44s, whereas HT1376 cells express CD44v isoforms (CD44-v3, CD44-v6, and CD44E (contains variant exons 8-10; Figure 2D) (Lokeshwar et al, 2005b, 2006; Golshani et al, 2008;
Jordan et al, 2016). Furthermore, while 253J-Lung cells have mutated/activated PI3-K (E545G), but wild-type AKT, PTEN and p53, HT1376 cells express wild-type PI3-K and AKT, but have mutated p53, and are PTEN null (Pagliaro et al, 2003; Pinto-Leite et al, 2014; Ross et al, 2016). As discussed below, the PI3-K/AKT pathway is activated by HA-HA receptor interaction.

In a scratch-wound assay with 253J-Lung cells, there was a significant inhibition of wound closure by $4 \mathrm{MU}$ in a dosedependent manner. The wound closure was nearly complete $(75.3 \pm 4.2 \%)$ in the untreated 253J-Lung cells within $24 \mathrm{~h}(\mathrm{~h})$ when compared with $4 \mathrm{MU}$-treated cells (e.g., 33.3. $\pm 3.1 \%$ for $0.4 \mathrm{~mm}$ concentration; $P<0.0001$; Figure 2A). Similarly, $4 \mathrm{MU}$ inhibited the chemotactic motility of 253J-Lung and HT1376 cells by $52 \%$ and $61 \%$, respectively $(P<0.0001$ in both cell types; Figure $2 \mathrm{~B})$. In addition, 4MU effectively abrogated invasive activity of 253J-Lung and HT1376 cells by $88.4 \%$ and $60.6 \%$, respectively (Figure 2C). In both cells lines, these inhibitory effects of $4 \mathrm{MU}$ were attenuated by $\mathrm{HA}$ addition (Figure $2 \mathrm{~B}$ and $\mathrm{C}$ ). These results show that the inhibitory effects of $4 \mathrm{MU}$ on $\mathrm{BCa}$ cell functions are primarily due to the inhibition of HA synthesis.

Effect of 4MU on apoptosis effectors. In 253J-Lung and HT1376 cells, 4MU induced activation of proapoptotic effectors (caspse-3, 8 and -9), Fas and FADD induction, and PARP cleavage in a dosedependent manner, but decreased antiapoptotic protein bcl-2 (Figure 2D). The levels of these pro- and antiapoptosis effectors were increased 2.5- to $>10$-fold in 4MU-treated cells $(P<0.0001$; Supplementary Table 2). Hyaluronic acid addition attenuated these effects of $4 \mathrm{MU}$ on various apoptosis effectors (Figure $3 \mathrm{~A}$ and Supplementary Table 3).

Targeting of HA signalling by 4MU. Cell surface interaction of HA with its receptors CD44 and RHAMM induces intracellular signalling that includes activation of PI3-K, AKT and EMT. In both cell lines, $4 \mathrm{MU}$ downregulated (1.5-10-fold) transcript levels of HA receptors CD44 (CD44s/CD44v) and RHAMM and EMT markers - $\beta$-catenin, Snail and Twist by 1.5 - to 10 -fold, but upregulated E-cadherin levels (4.5-7-fold; $P<0.0001$; Supplementary Figure 2B). At the protein level, in both cell lines, $4 \mathrm{MU}$ downregulated CD44 and RHAMM and phosphorylation of $\mathrm{AKT}(\mathrm{S} 472)$ in a dose-dependent manner. Consequently, 4MU also downregulated phosphorylated glycogen synthase-3 kinase (pGSK$3 \alpha / \beta), \mathrm{p} \beta$-catenin(S552), Snail and Twist levels but upregulated $\mathrm{p} \beta$-catenin (T41/S45) and E-cadherin levels (Figure 2D and Supplementary Tables 2 and 3). Post-translationally, $\beta$-catenin activation is regulated by AKT and GSK-3 $\alpha / \beta$ (Xu et al, 2015a, b). Phosphorylation at S552 induces nuclear localisation of $\beta$-catenin, but phosphorylation at T41/S45 by activated GSK-3 $\alpha / \beta$ causes its degradation; GSK-3 $\alpha / \beta$ itself is phosphorylated by activated AKT and consequently degraded (Takahashi-Yanaga, 2013). Activated $\beta$-catenin upregulates Snail and Twist via the $\beta$-catenin TCF/LEF complex, this in turn negatively regulates E-cadherin expression in the presence of $\mathrm{HA}$, the effect of $4 \mathrm{MU}$ on $\mathrm{HA}$ receptor and AKT activation, and downstream EMT effectors were attenuated (Figure $3 \mathrm{~A}$ and Supplementary Table 3 ). This suggests that the effect of $4 \mathrm{MU}$ on the observed signalling events is due to the inhibition of HA synthesis.

Effect of 4MU on PI3-K/AKT axis. To confirm the effect of 4MU on HA-receptor-mediated AKT activation and downstream signalling in 253J-Lung cells, we overexpressed myristoylated AKT (mAKT), which is constitutively active. Myristoylated AKT overexpression attenuated $4 \mathrm{MU}$-induced alterations in apoptosis effectors, inhibition of cell growth and induction of apoptosis (Figure $3 \mathrm{~B}$ and $\mathrm{C}$ and Supplementary Table 3). Furthermore, constitutively active AKT in mAKT transfectants abrogated the effects of $4 \mathrm{MU}$ on EMT determinants - downregulation of $\mathrm{p} \beta$ catenin(S552), Snail, Twist levels and upregulation of $\mathrm{p} \beta$-catenin 

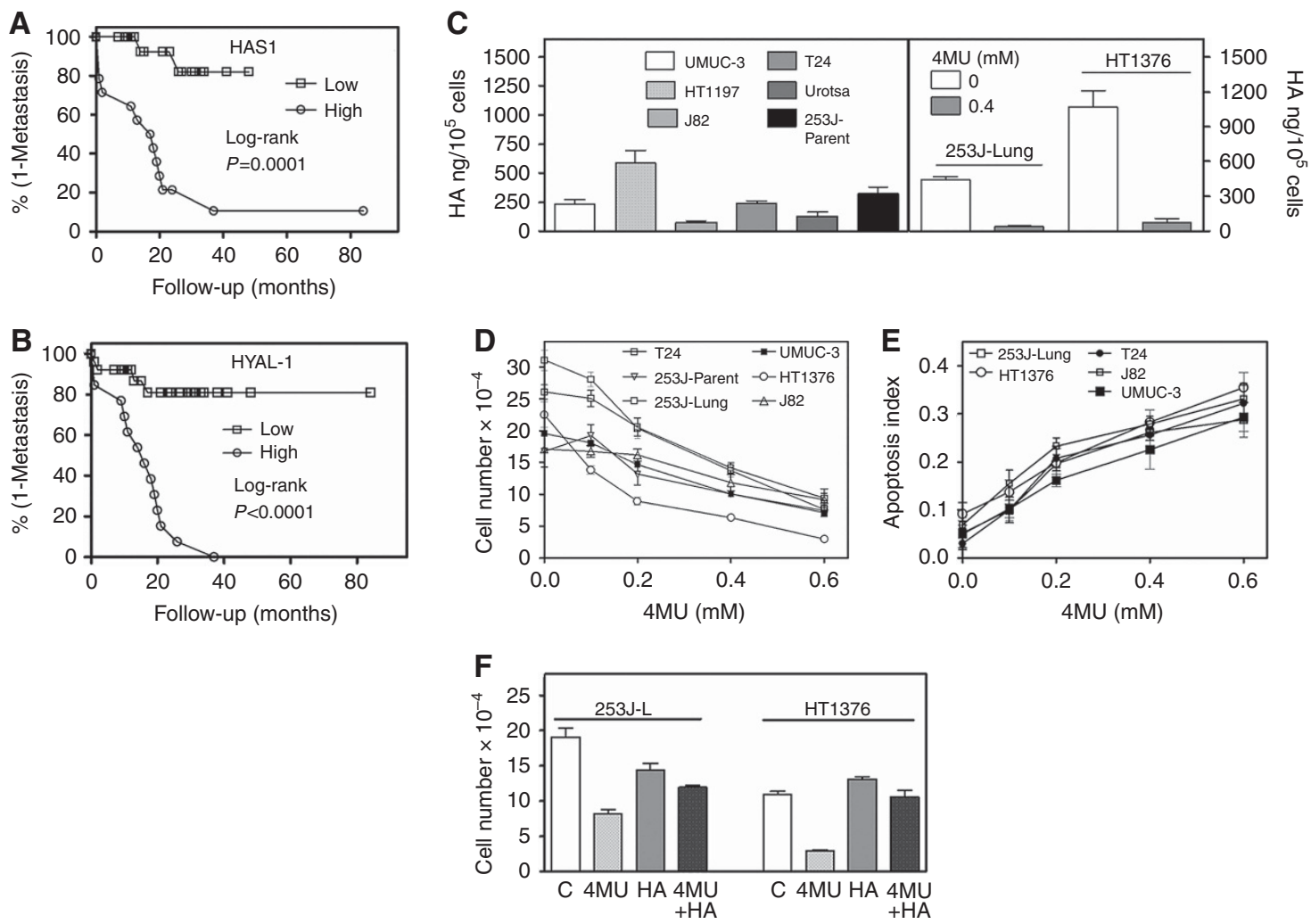

Figure 1. Stratification of clinical data to predict metastasis and the effect of $4 \mathrm{MU}$ on HA synthesis, cell proliferation and apoptosis. (A and B) Kaplan-Meier plots. Stratification of the cohort to predict metastasis based on transcript levels of HAS1 and HYAL-1. Both transcript levels significantly associated with metastasis (as shown in Table 1). Receiver operating characteristic curve was generated for each marker to determine the optimal cutoff limits based on the Youden's index. These cutoff limits were then used to stratify high-and low-marker expression for generating Kaplan-Meier curves. (C) Hyaluronic acid levels in bladder cell conditioned media. Hyaluronic acid levels ( $\mathrm{ng} \mathrm{ml} \mathrm{m}^{-1}$ ) in the $\mathrm{CM}$ of BCa and a normal urothelial line (UROtsa) were measured by an ELISA-like assay in triplicate or quadruplicate and normalised to cell number. Hyaluronic acid levels were also measured in $\mathrm{CM}$ following $48 \mathrm{~h}$ treatment of cells with $0.4 \mathrm{~mm} 4 \mathrm{MU}$. Data are represented as mean \pm s.d. (D) Bladder cancer cells were treated with various concentrations of $4 \mathrm{MU}$ for $72 \mathrm{~h}$ and viable cells were counted. (E) Measurement of apoptosis in BC cells treated with $4 \mathrm{MU}$ for $48 \mathrm{~h}$. Data are represented as mean \pm s.d. (triplicate). (F) The 253J-Lung and HT1376 cells were treated with $4 \mathrm{MU}(0.4 \mathrm{mM})$ in the presence or absence of $\mathrm{HA}\left(50 \mathrm{~g} \mathrm{ml}^{-1}\right)$ for $72 \mathrm{~h}$. Following incubation, viable cells were counted. Data in (D)-(F): Mean \pm s.d. (quadruplicate).

(T41/S45) and E-cadherin levels (Figure 3B and Supplementary Table 3). Consequently, mAKT overexpression also prevented inhibition of invasive activity by $4 \mathrm{MU}$ (Figure 3D).

Because 4MU inhibits AKT activation, we determined whether 4MU downregulated PI3-K activity. As shown in Figure 4A, in 4MUtreated 253J-Lung cells, PI3-K activity was downregulated by $\sim 90 \%$ (pPI3-K to total PI3-K ratio: control, $0.59 \pm 0.01$; $4 \mathrm{MU}, 0.05 \pm 0.004$; $P<0.0001)$. Since PI3-K/AKT signalling induces NF- $\kappa \mathrm{B}$ activity by causing degradation of $\mathrm{I} \kappa \mathrm{B}$, we examined the transcriptional activity of NF- $\kappa \mathrm{B}$. As shown in Figure 4A, 4MU inhibited NF- $\kappa \mathrm{B}$ promoter luciferase-reporter activity in both 253J-Lung and HT1376 cells by $40-50 \%$ following $16 \mathrm{~h}$ treatment $(P<0.0001)$. Treatment of 253JLung cells with a combination of $4 \mathrm{MU}$ with LY29400, a PI3-K inhibitor, synergistically inhibited cell growth by $>90 \%(P<0.0001$; Figure 4B). This growth inhibition was caused by increased apoptosis; the combination caused a 6.3-fold induction of apoptosis when compared with an $\sim 2$-fold induction by $4 \mathrm{MU}$ and LY29400 alone (Figure $4 \mathrm{~B}$ ). We have previously shown that in prostate and BCa cells, PI3-K and CD44 forms a complex, and this complex has been shown to induce PI3-K activation (Yates et al, 2013; Jordan et al, 2016). A proximal ligation assay (PLA) followed by confocal microscopy showed that $4 \mathrm{MU}$ treatment inhibited the CD44/PI3-K complex by more than $90 \%$ (Figure $4 \mathrm{C}$ ).

Antitumour effects of 4MU. To determine whether 4MU inhibited tumour growth in the HT1376 xenograft model, treatment was started once the tumours reached $\sim 100 \mathrm{~mm}^{3}$, that is, day 22. As shown in Figure 4D, 4MU significantly inhibited tumour growth at 200 and $400 \mathrm{mg} \mathrm{kg}^{-1}$ doses, even after $4 \mathrm{MU}$ treatment was stopped on day 35. The differences in tumour volume $\left(\mathrm{mm}^{3}\right)$ in the vehicle group (day $35 ; 770.8 \pm 218.9$ ) and $4 \mathrm{MU}$ treatment groups (day 50; 200: 216.6 $\pm 44.1 ; 400$ : $128.6 \pm 61.5)$ were significant $(P<0.0001)$. As we have reported previously, $4 \mathrm{MU}$ did not affect animal weight (Figure $4 \mathrm{E}$ ). Immunohistochemistry on HT1376 tumour tissues confirmed the downregulation of $\beta$-catenin, $\mathrm{p} \beta$-catenin (S552) and the upregulation of cleaved caspase- 3 and E-cadherin in the $4 \mathrm{MU}$ treatment group ( $400 \mathrm{mg} \mathrm{kg}^{-1}$ ), when compared with the vehicle group (Figure 4F). Furthermore, MVD per high power field was significantly reduced in the $4 \mathrm{MU}$ treatment group $(0.6 \pm 0.72)$ when compared with the vehicle group $(9 \pm 2.3) \quad(P<0.001$; Figure $4 \mathrm{G})$. We also evaluated the efficacy of $4 \mathrm{MU}$ in preventing bladder tumour initiation and growth. In the 253J-Lung model, oral treatment with $4 \mathrm{MU}$ starting on the day of tumour cell injection also prevented tumour growth. 4-Methylumbelliferonetreated animals did not form palpable tumours; tumour volumes $\left(\mathrm{mm}^{3}\right)$ on day 33 for vehicle: $748 \pm 348.4$; 4MU: $24.2 \pm 15.7$.

EMT marker expression and its correlation to HA family marker levels in BCa specimens. Measurement of EMT marker expression in bladder specimens, in which we had evaluated HA family marker expression, showed that $\beta$-catenin, Twist and Snail 
A
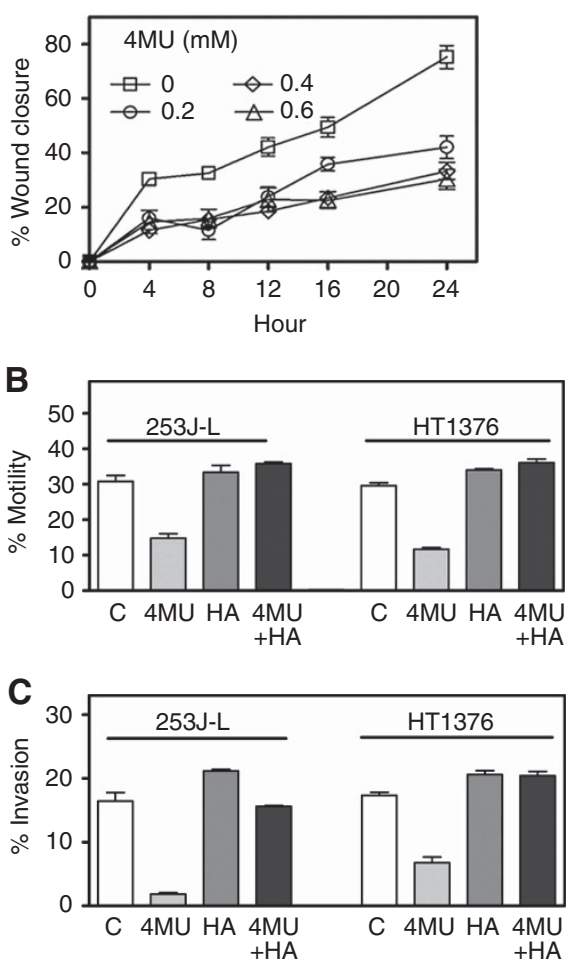

D

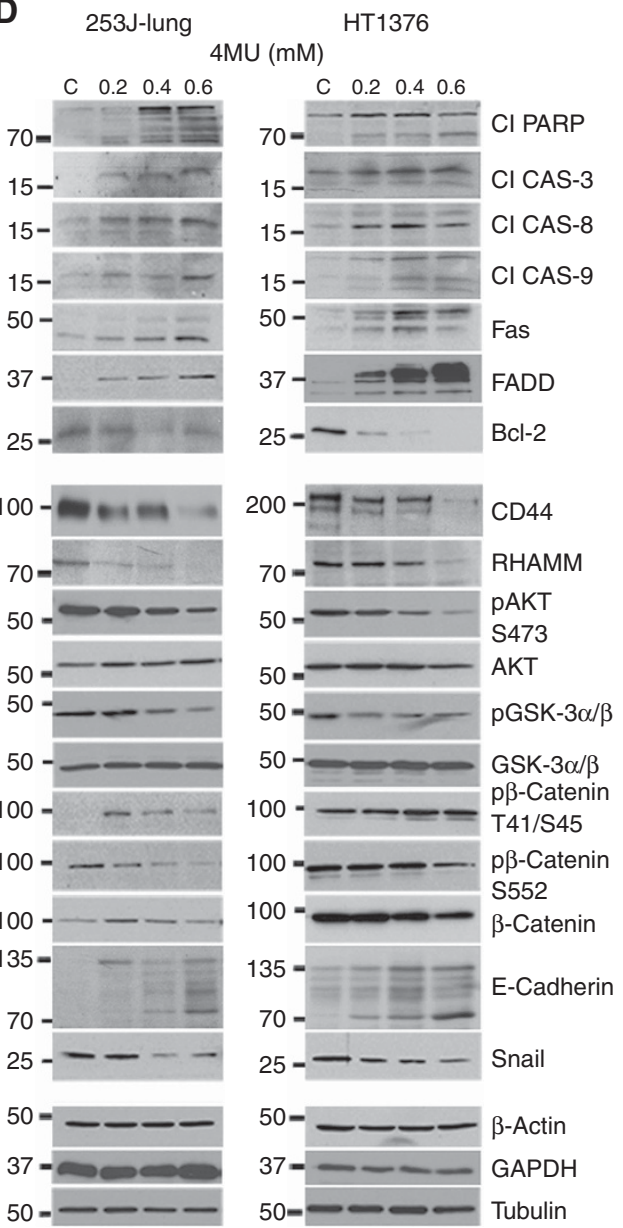

Figure 2. Effect of $4 \mathrm{MU}$ on migration, chemotactic motility, invasion and gene expression. (A) Scratch-wound motility assay: 253J-Lung cells were incubated with $4 \mathrm{MU}(0$ and $0.4 \mathrm{~mm})$ and were photographed at various time intervals after creating a scratch wound. The photographs were used to estimate \% wound closure. (B and $\mathbf{C})$ Determination of chemotactic motility and invasion of BCa cells treated with $4 \mathrm{MU}(0$ and $0.4 \mathrm{mM})$ and/or HA $50 \mu \mathrm{g} \mathrm{ml}^{-1}$. \% Motility (B) or \% invasion (C) were calculated after 18 and $48 \mathrm{~h}$ incubations, respectively. Data are represented as mean \pm s.d. (triplicate). $P<0.001$; untreated and $4 \mathrm{MU}$-treated BCa cells; $P>0.05$ between HA-treated and $4 \mathrm{MU}+\mathrm{HA}$-treated cells. (D) Immunoblot analysis of $\mathrm{BCa}$ cells treated with $4 \mathrm{MU}(0-0.6 \mathrm{~mm})$ for $48 \mathrm{~h}$; loading controls: $\beta$-actin, glyceraldehyde-3-phosphate dehydrogenase (GAPDH), tubulin.

transcript levels were significantly upregulated but E-cadherin levels were significantly downregulated in BCa tissues, when compared with normal bladder tissues (Figure 5A and $\mathrm{B}$ ). However, only Twist transcript levels were significantly higher (10-fold) in BCa tissues from patients who developed metastasis, when compared with those who did not (Figure 5B). In univariate analysis, Twist levels significantly correlated with metastasis and Kaplan-Meier plot showed that Twist levels significantly stratified $\mathrm{BCa}$ patients into low- and high-risk groups for developing metastasis (Table 1 and Figure 5C). In the TCGA data set, upregulation of $\beta$-catenin, Snail and Twist transcript levels significantly correlated with overall survival (Table 1). Furthermore Snail and Twist transcript levels stratified patients into low- and high-risk groups for survival (Figure 5D and E).

As HA signalling induces the expression of $\beta$-catenin, Snail and Twist and downregulates E-cadherin expression, we examined whether the expression of HA family markers correlated with that of EMT markers. As shown in Supplementary Table 4, although there were differences in the correlation of individual HA family markers with EMT markers, in both sets of specimens, upregulation of HA family significantly correlated with the upregulation of $\beta$-catenin, Snail and Twist levels $(P \leqslant 0.01)$. Furthermore, there was a significant inverse correlation between HA family upregulation and E-cadherin downregulation in BCa specimens $(P<0.01-P<0.001$ for correlations). The studies in clinical specimens support our mechanistic studies that oncogenic HA signalling supports an aggressive phenotype by upregulating EMT determinants.

\section{DISCUSSION}

The present study demonstrates that a biomarker-based targeted treatment strategy that involves HA family biomarkers and their targeting by a non-toxic dietary supplement, $4 \mathrm{MU}$, can potentially be useful in the treatment of $\mathrm{BCa}$. In this study, multiple approaches encompassing functional, mechanistic and xenograft studies as well as biomarker analyses show that HA family molecules associate with and are drivers of $\mathrm{BCa}$ growth and progression. Our study confirms that the antitumour activity of $4 \mathrm{MU}$ is largely due to its inhibitory effects on HA synthesis. In the presence of HA, the phenotypic readouts such as inhibition of growth, motility and invasion by $4 \mathrm{MU}$ are attenuated. Furthermore, HA also prevented 4MU from exerting its effects on PI3-K/ AKT signalling and EMT markers; these observations establish the targeted therapeutic efficacy of $4 \mathrm{MU}$. These results are consistent with our previous report, in which we demonstrated that $4 \mathrm{MU}$ has significant chemopreventive and therapeutic efficacy in prostate 
A
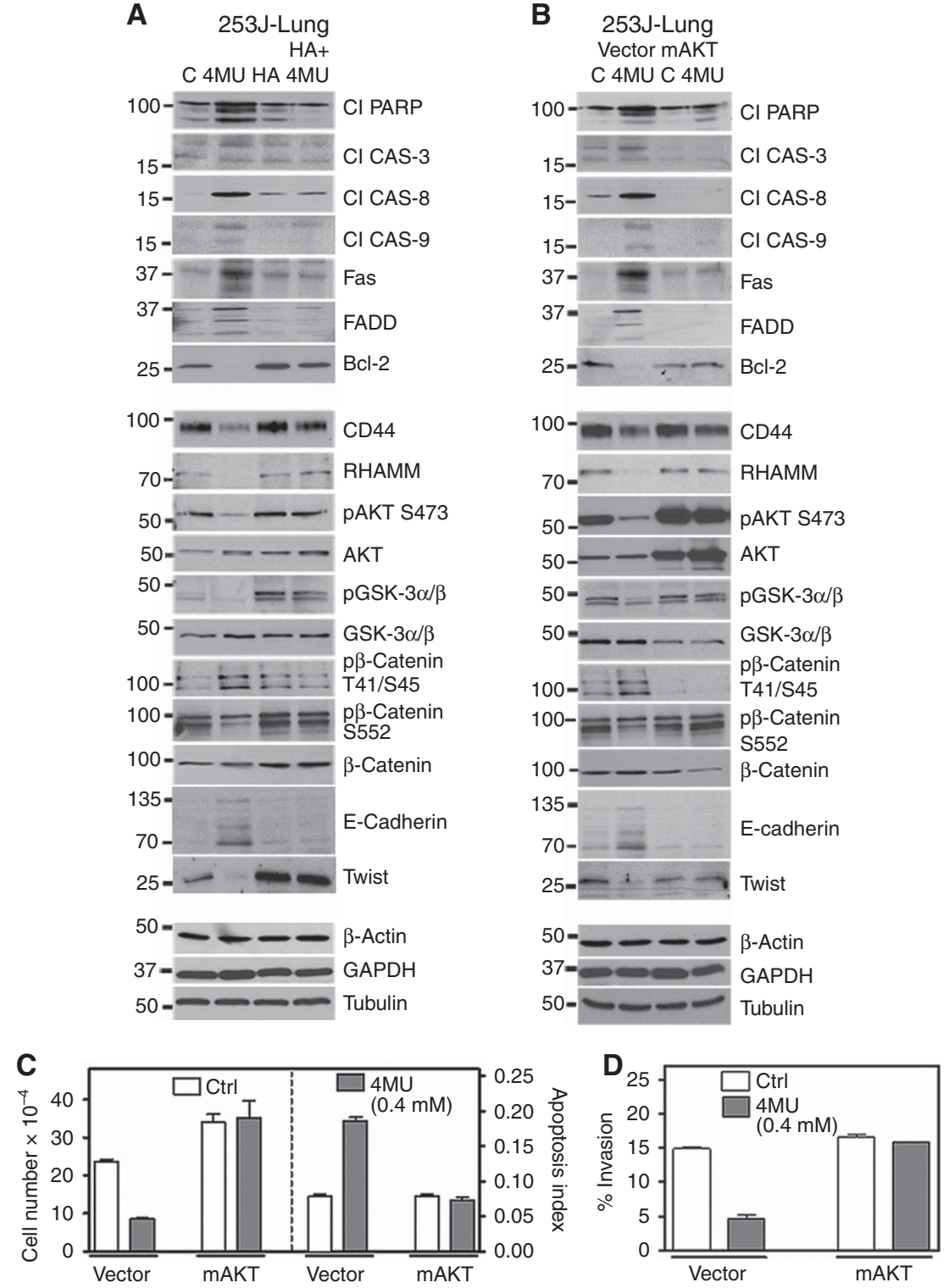

Figure 3. Effect of HA and myr-AKT expression on 4MU-induced effects. (A) Immunoblot analysis of 253J-Lung cells treated with 4MU (0, 0.4 mM) and/or HA (50 $\left.\mu \mathrm{g} \mathrm{ml}^{-1}\right)$; $\beta$-actin, GAPDH, Tubulin: loading controls. (B). Immunoblot analysis of vector and mAKT transfectants; $\beta$-actin, GAPDH, Tubulin: loading controls. (C). 253J-Lung vector and mAKT transient transfectants were treated with $4 \mathrm{MU}(0,0.4 \mathrm{mM})$. Following $48 \mathrm{~h}$ incubation, viable cells were counted (left panel) and also subjected to apoptosis assay (right panel). (D). Transient transfectants treated with $4 \mathrm{MU}$ were assayed for invasion. Data in $\mathbf{C}$ and $\mathbf{D}$ : Mean \pm s.d. (triplicate); $P<0.001$ in untreated and $4 \mathrm{MU}$ treated samples for vector transfectants; $P>0.05$ for mAKT transfectants.

cancer models (Yates et al, 2015). It is noteworthy that HA and HYAL-1 expression is not only elevated in prostate cancer but also correlates with biochemical recurrence (Posey et al, 2003; Ekici et al, 2004; Gomez et al, 2009). The association of the HA family molecules with the aggressiveness of cancer, as well as the mechanism of action and efficacy of $4 \mathrm{MU}$ in two different cancer systems, suggest that targeting of HA signalling by a nontoxic orally bioavailable supplement such as $4 \mathrm{MU}$, is likely to be effective in other cancer systems in which the expression of the HA family molecules is elevated. As the expression of HA family is elevated in a variety of cancers (Lokeshwar et al, 2002; Kramer et al, 2011; Chi et al, 2012; Peng et al, 2016), 4MU should potentially have a broader applicability as a targeted antitumour agent. To this effect, in this study $4 \mathrm{MU}$ showed significant antitumour efficacy in the therapeutic (treatment starting when tumours were palpable) and chemopreventive (253J-Lung model) settings. 4-Methylumbelliferone has also shown antitumour efficacy in a few other cancer models, although an in-depth analysis of its mechanism of action has been examined only in one other study from our group involving preclinical models of prostate cancer (Lokeshwar et al, 2010; Arai et al, 2011; Piccioni et al, 2012; Yates et al, 2015; Nagase et al, 2016; Ikuta et al, 2017). As a dietary supplement and in small clinical studies, the $4 \mathrm{MU}$ dose is about $1.5 \mathrm{~g}$ per day (Camarri and Marchettini, 1988; Abate et al, 2001). This dose is equivalent to the doses used in this study. Pharmacokinetics of $4 \mathrm{MU}$ shows rapid clearance by biotransformation into glucuronide (major) and sulphated derivatives; the glucuronidated derivative is inactive and excreted in urine (Kuipers et al, 2016). Based on the favourable toxicity profile and efficacy in HA family expressing tumours, $4 \mathrm{MU}$ could be potentially tested in clinical trials.

The EMT phenotype is a critical hallmark of cancer metastasis. Our study demonstrates a link between HA signalling and EMT signature (i.e., $\beta$-catenin upregulation/activation and E-cadherin downregulation) via the PI3-K/AKT axis. Furthermore, inhibition 

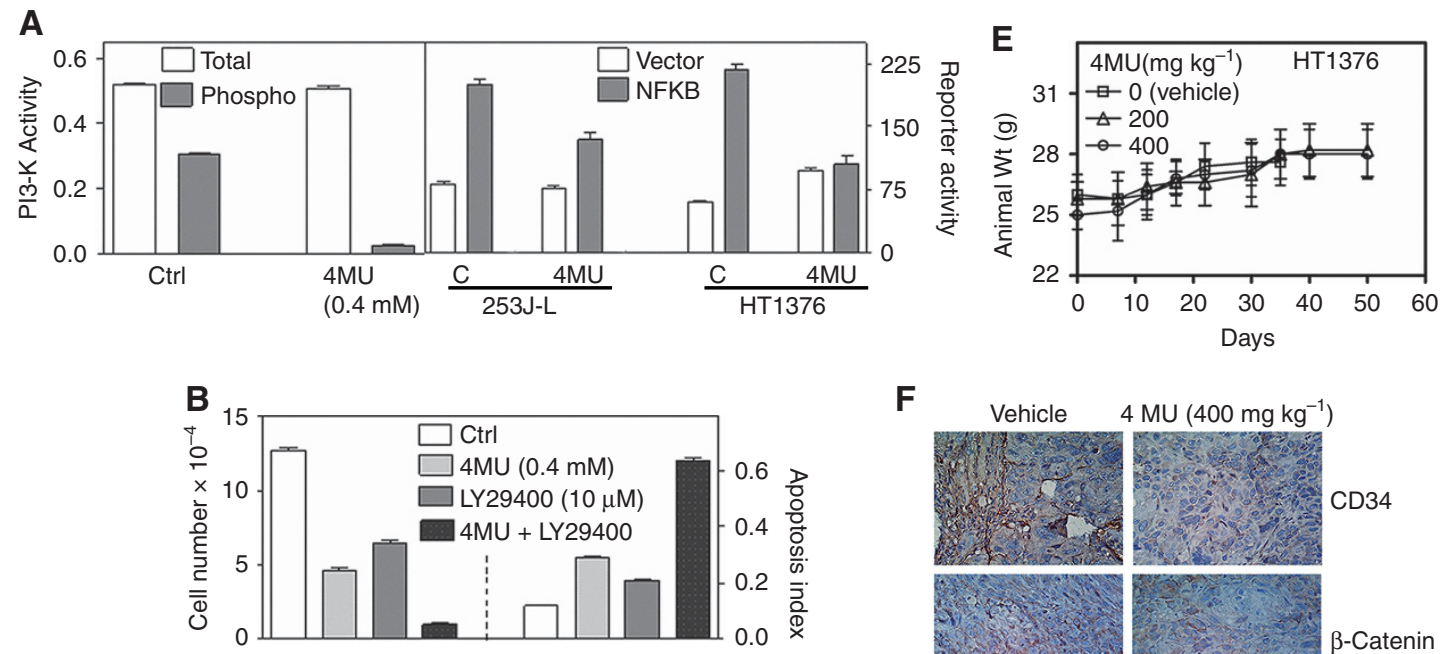

$\mathbf{F}$
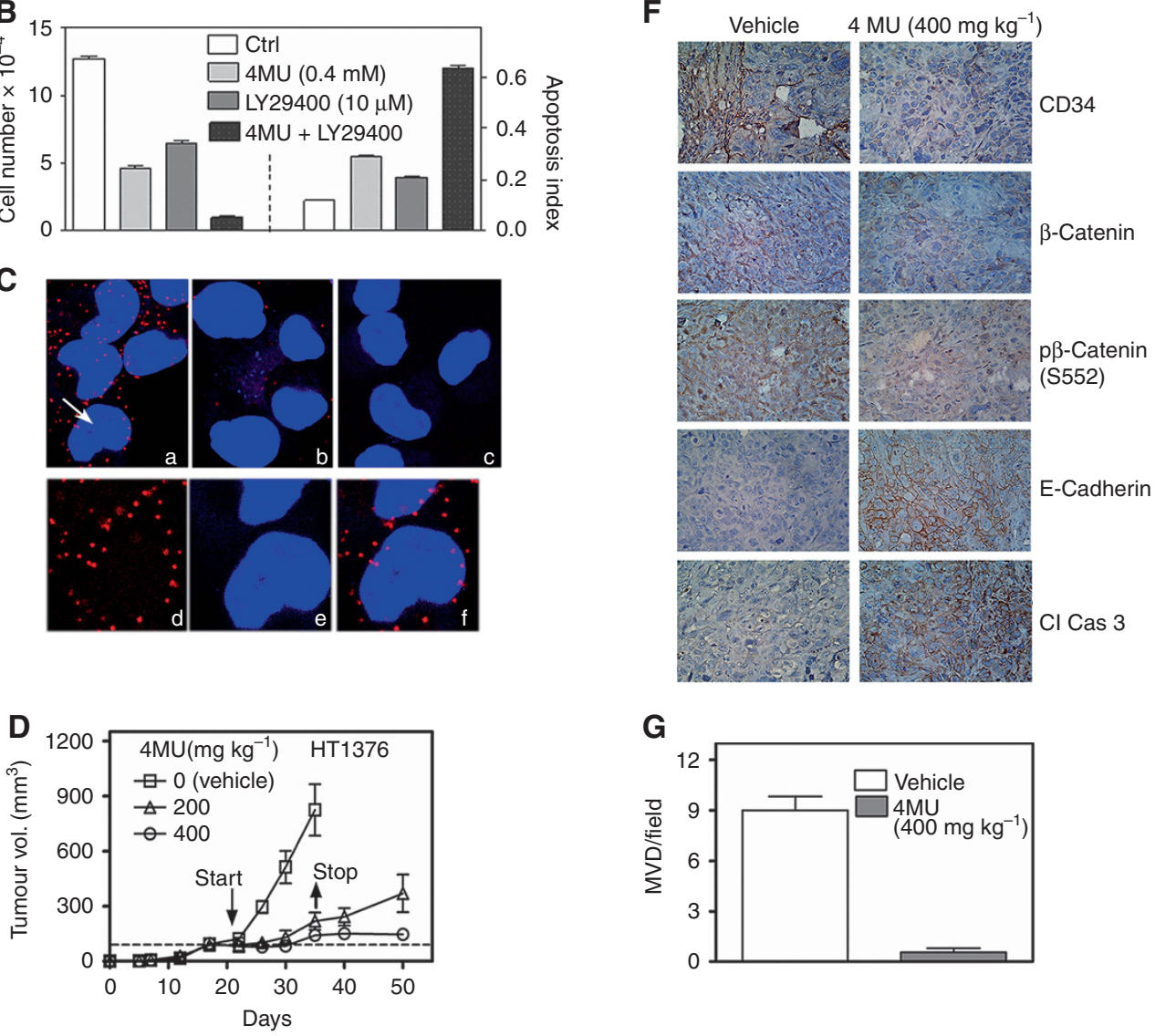

G

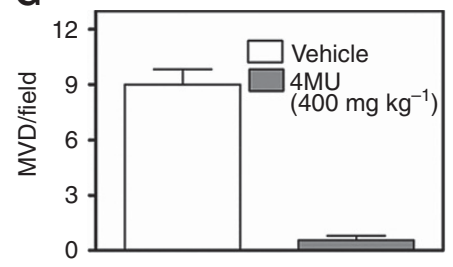

Figure 4. Effect of $4 \mathrm{MU}$ on $\mathrm{PI} 3-\mathrm{K} / \mathrm{mAKT}$ signalling, CD44/PI3-K complex, and bladder tumour models. (A) Left panel: Measurement of PI-3K activity by an ELISA, in 253J-Lung cells treated with or without $4 \mathrm{MU}(0.4 \mathrm{mM})$ for $24 \mathrm{~h}$. Data: Mean \pm s.d. (triplicate). Right panel: $253 \mathrm{~J}$-Lung and HT1376 cells were subjected to NF- $\kappa$ B reporter assay. Data are represented as mean \pm s.d. (triplicate); $P<0.001$ for both cell lines. (B) $253 \mathrm{~J}$-Lung cells were treated with $4 \mathrm{MU}$ and/or PI3-K inhibitor LY29400 for $48 \mathrm{~h}$. Following incubation viable cells were counted (plotted on left axis) and also subjected to apoptosis assay (data plotted on right axis). Data are represented as mean \pm s.d. (quadruplicate); $P<0.001$. (C) Proximal ligation assay for visualising a complex between PI3-K and CD44. 253J-Lung cells treated with 4-MU (0 and $0.4 \mathrm{~mm})$ for $24 \mathrm{~h}$ were subjected to PLA using antiPI3-K ( $\alpha$; p85 subunit) and anti-CD44 antibodies. Confocal microscopy images at $\times 630$ magnification are shown. (a and b) Cells treated with 0 (a) and $0.4 \mathrm{mM} 4 \mathrm{MU}$ (b); (c) IgG control. Red dots in PLA show the CD44 and PI3-K complex. (d-f) A cell indicated by an arrow in the untreated (0 4MU) sample: (d) PLA (CD44/PI3-K; red channel); (e) nucleus (4',6-diamidino-2-phenylindole (DAPI) staining; blue); ( $f$ merged. Note the CD44/PI3-K complex appears on the cell membrane. (D) Athymic mice were implanted subcutaneously with HT1376 cells. When tumour size reached $100 \mathrm{~mm}^{3}$, mice were orally gavaged daily with vehicle ( $2 \%$ sucrose) or $4 \mathrm{MU}\left(200\right.$ or $\left.400 \mathrm{mg} \mathrm{kg}^{-1}\right)$ until day 35 . Data are represented as mean \pm s.d. (E) Weight of animals in the vehicle and treatment groups of HT1376 xenograft. Data: are represented as mean \pm s.d. (F) Immunohistochemical analysis. Tumour tissues frm the vehicle and $4 \mathrm{MU}$ treatment $\left(400 \mathrm{mg} \mathrm{kg}^{-1}\right)$ groups were subjected to $\mathrm{CD} 34, \beta$-catenin, $\mathrm{p} \beta$-catenin( $\left.\mathrm{S} 552\right)$, E-cadherin and cleaved caspase-3 staining using immunohistochemistry; magnification: $\times 400$. (G) Microvessel density. Microvessels were counted under high power field $(n=10)$. Data are represented as mean \pm s.d.

of a complex formation between CD44 and PI3-K by 4MU shows that by inhibiting HA synthesis, $4 \mathrm{MU}$ abrogates the first step in HAsignalling-mediated induction of EMT signature. A salient finding of our study is the analysis of the expression of HA family and EMT effectors in the same cohort of specimens and a TCGA database of BCa patients. These analyses confirm the prognostic potential of HA synthases and HYAL-1 in predicting metastasis and survival (DSM or overall) in BCa patients. As HYAL-1 degrades HA into angiogenic fragments, it is the tumour-associated HA-HAase system that is responsible for BCa growth and progression (Lokeshwar et al, 1997, 2001, 2005b; Jordan et al, 2016). As both the tissue and TCGA data analyses show that HA synthases are differentially expressed in $\mathrm{BCa}$ tissues, targeting of individual HA synthases is unlikely to be effective in blocking the tumour-associated HA-HAase system, and therefore $\mathrm{HA}$ inhibitors such as $4 \mathrm{MU}$ would make a better treatment option to control BCa. 

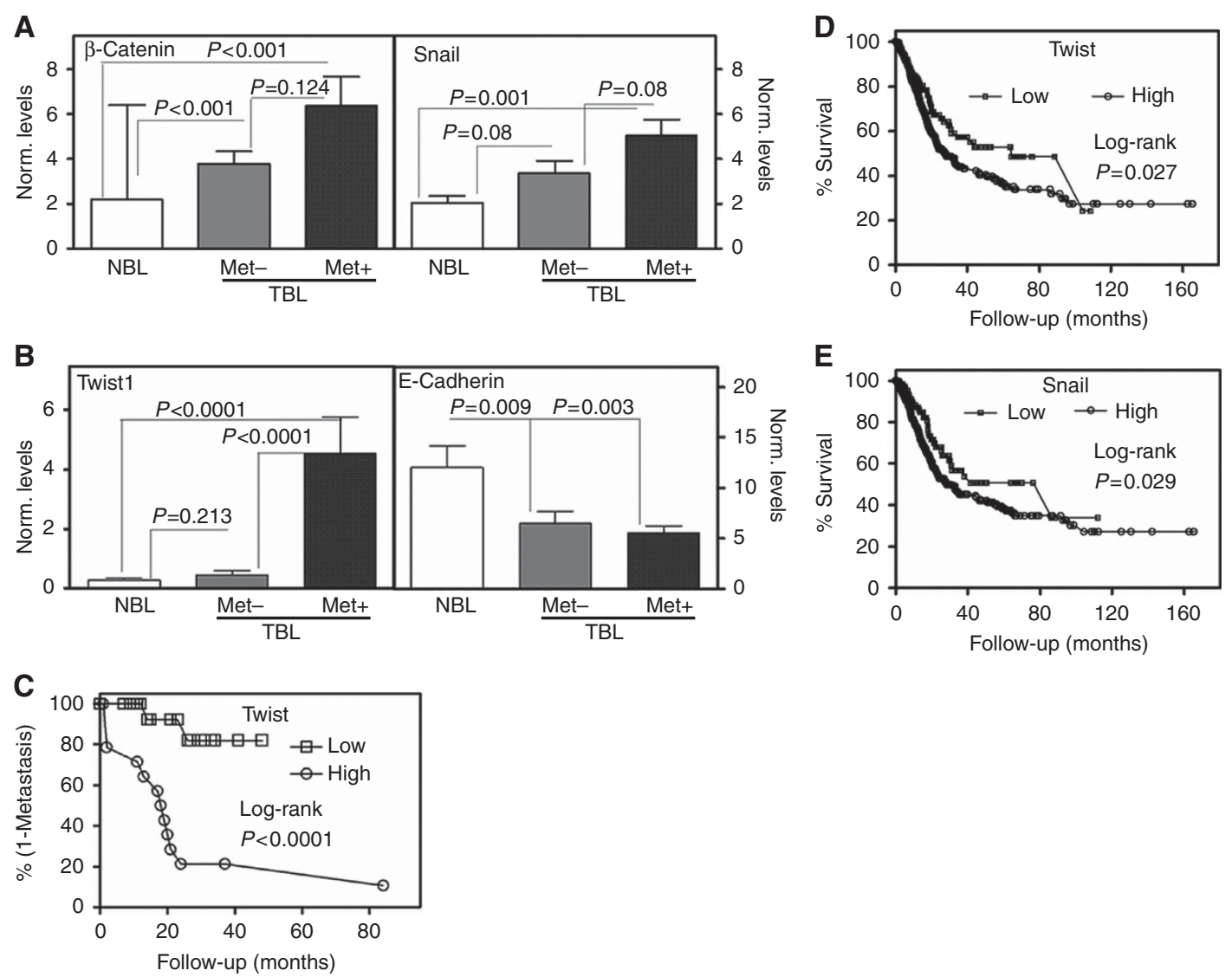

Figure 5. Analysis of EMT markers in bladder specimens. (A) and (B) mRNA levels of $\beta$-catenin, Snail (A), Twist and E-cadherin (B) were measured by QPCR in bladder specimens from set 1 . Bladder cancer specimens included patients who developed (met + ) and those who did not develop (met -) metastasis. Differences between NBL and TBL specimens from patients who either developed (met + ) or did not develop (met -) metastasis were compared using the Mann-Whitney U-test because the data showed a non-normal distribution; two-tailed P-values. Data are represented as mean \pm s.e.m. (C) Stratification of the set 1 cohort to predict metastasis based on Twist transcript levels. (D and E) Twist and Snail markers reported in set 2. Receiver operating characteristic curve was generated for each marker to determine the optimal cutoff limits based on the Youden's index. These cutoff limits were then used to stratify high- and low-marker expression for generating Kaplan-Meier curves.

Our study also identified Twist as a prognostic marker for predicting metastasis and overall survival in BCa patients. The prognostic potential of Twist has been reported previously (Fantony et al, 2015; Singh et al, 2016). In this study, we observed some differences in our clinical specimen data set and the TCGA data. For example, in our clinical specimens, HAS1, HYAL-1 and Twist transcript levels showed the potential to predict metastasis and/or DSM. In the TCGA database HAS1, HAS2, HAS3, HYAL1, RHAMM and EMT markers, except E-cadherin, correlated with survival in univariate analysis and/or stratified patients into lowand high-risk groups for overall survival. The reasons for this discrepancy may be the parameters used for correlation metastasis and DSM in our data set and overall survival in the TCGA data set. Nevertheless, in both data sets, the expression of individual HA family markers significantly correlated with different EMT markers. These observations on clinical specimens provide credence to the mechanistic studies that HA signalling regulates EMT signature, and therefore aggressive phenotype in BCa.

In summary, our study demonstrates that HA family biomarkers promote $\mathrm{BCa}$ growth and progression very likely by upregulating the EMT phenotype. Certain HA family molecules (i.e., HAS1, HYAL-1) and EMT markers (i.e., Twist) can potentially be useful in predicting outcome in $\mathrm{BCa}$ patients and perhaps for selecting patients who might benefit from treatments that block HA signalling, such as 4MU. Therefore, the HA family is a potential candidate for developing biomarker-driven targeted non-toxic oral treatment for $\mathrm{BCa}$.

\section{ACKNOWLEDGEMENTS}

This work was supported by R01CA72821-10 (to VBL), R21CA184018-02 (to VBL) and 5R01CA176691-02 (to VBL). MSHennig was a fellow of the Biomedical Exchange Program, International Academy of Life Sciences.

\section{CONFLICT OF INTEREST}

The authors declare no conflict of interest.

\section{REFERENCES}

Abate A, Dimartino V, Spina P, Costa PL, Lombardo C, Santini A, Del Piano M, Alimonti P (2001) Hymecromone in the treatment of motor disorders of the bile ducts: a multicenter, double-blind, placebo-controlled clinical study. Drugs Exp Clin Res 27: 223-231.

Arai E, Nishida Y, Wasa J, Urakawa H, Zhuo L, Kimata K, Kozawa E, Futamura N, Ishiguro N (2011) Inhibition of hyaluronan retention by 4-methylumbelliferone suppresses osteosarcoma cells in vitro and lung metastasis in vivo. Br J Cancer 105: 1839-1849.

Camarri E, Marchettini G (1988) Hymecromone in the treatment of symptoms following surgery of the bile ducts. Recent Prog Med 79: 198-202. 
Chanmee T, Ontong P, Itano N (2016) Hyaluronan: a modulator of the tumor microenvironment. Cancer Lett 375: 20-30.

Chi A, Shirodkar SP, Escudero DO, Ekwenna OO, Yates TJ, Ayyathurai R, Garcia-Roig M, Gahan JC, Manoharan M, Bird VG, Lokeshwar VB (2012) Molecular characterization of kidney cancer: association of hyaluronic acid family with histological subtypes and metastasis. Cancer 118: 2394-2402.

Ekici S, Cerwinka WH, Duncan R, Gomez P, Civantos F, Soloway MS, Lokeshwar VB (2004) Comparison of the prognostic potential of hyaluronic acid, hyaluronidase (HYAL-1), CD44v6 and microvessel density for prostate cancer. Int J Cancer 112: 121-129.

Fantony JJ, Abern MR, Gopalakrishna A, Owusu R, Jack Tay K, Lance RS, Inman BA (2015) Multi-institutional external validation of urinary TWIST1 and NID2 methylation as a diagnostic test for bladder cancer. Urol Oncol 33: 387 e1-6.

Golshani R, Hautmann SH, Estrella V, Cohen BL, Kyle CC, Manoharan M, Jorda M, Soloway MS, Lokeshwar VB (2007) HAS1 expression in bladder cancer and its relation to urinary HA test. Int J Cancer 120: 1712-1720.

Golshani R, Lopez L, Estrella V, Kramer M, Iida N, Lokeshwar VB (2008) Hyaluronic acid synthase-1 expression regulates bladder cancer growth, invasion, and angiogenesis through CD44. Cancer Res 68: 483-491.

Gomez CS, Gomez P, Knapp J, Jorda M, Soloway MS, Lokeshwar VB (2009) Hyaluronic acid and HYAL-1 in prostate biopsy specimens: predictors of biochemical recurrence. J Urol 182: 1350-1356.

Guin S, Ru Y, Agarwal N, Lew CR, Owens C, Comi GP, Theodorescu D (2016) Loss of glycogen debranching enzyme AGL drives bladder tumor growth via induction of hyaluronic acid synthesis. Clin Cancer Res 22: 1274-1283.

Hautmann SH, Lokeshwar VB, Schroeder GL, Civantos F, Duncan RC, Gnann R, Friedrich MG, Soloway MS (2001) Elevated tissue expression of hyaluronic acid and hyaluronidase validates the HA-HAase urine test for bladder cancer. J Urol 165: 2068-2074.

Ikuta K, Ota T, Zhuo L, Urakawa H, Kozawa E, Hamada S, Kimata K, Ishiguro N, Nishida Y (2017) Antitumor effects of 4-methylumbelliferone, a hyaluronan synthesis inhibitor, on malignant peripheral nerve sheath tumor. Int J Cancer 140: 469-479.

Jordan AR, Lokeshwar SD, Lopez LE, Hennig M, Chipollini J, Yates T, Hupe MC, Merseburger AS, Shiedlin A, Cerwinka WH, Liu K, Lokeshwar VB (2016) Antitumor activity of sulfated hyaluronic acid fragments in pre-clinical models of bladder cancer. Oncotarget 8: 24262-24274.

Jordan AR, Racine RR, Hennig MJ, Lokeshwar VB (2015) The role of CD44 in disease pathophysiology and targeted treatment. Front Immunol 6: 182.

Kakizaki I, Kojima K, Takagaki K, Endo M, Kannagi R, Ito M, Maruo Y, Sato H, Yasuda T, Mita S, Kimata K, Itano N (2004) A novel mechanism for the inhibition of hyaluronan biosynthesis by 4-methylumbelliferone. J Biol Chem 279: 33281-33289.

Kakizaki I, Takagaki K, Endo Y, Kudo D, Ikeya H, Miyoshi T, Baggenstoss BA, Tlapak-Simmons VL, Kumari K, Nakane A, Weigel PH, Endo M (2002) Inhibition of hyaluronan synthesis in Streptococcus equi FM100 by 4-methylumbelliferone. Eur J Biochem 269: 5066-5075.

Karousou E, Misra S, Ghatak S, Dobra K, Gotte M, Vigetti D, Passi A, Karamanos NK, Skandalis SS (2016) Roles and targeting of the HAS/ hyaluronan/CD44 molecular system in cancer. Matrix Biol 59: 3-22.

Kramer MW, Escudero DO, Lokeshwar SD, Golshani R, Ekwenna OO, Acosta K, Merseburger AS, Soloway M, Lokeshwar VB (2011) Association of hyaluronic acid family members (HAS1, HAS2, and HYAL-1) with bladder cancer diagnosis and prognosis. Cancer 117: 1197-1209.

Kramer MW, Golshani R, Merseburger AS, Knapp J, Garcia A, Hennenlotter J, Duncan RC, Soloway MS, Jorda M, Kuczyk MA, Stenzl A, Lokeshwar VB (2010) HYAL-1 hyaluronidase: a potential prognostic indicator for progression to muscle invasion and recurrence in bladder cancer. Eur Urol 57: 86-93.

Kuipers HF, Nagy N, Ruppert SM, Sunkari VG, Marshall PL, Gebe JA, Ishak HD, Keswani SG, Bollyky J, Frymoyer AR, Wight TN, Steinman L, Bollyky PL (2016) The pharmacokinetics and dosing of oral 4-methylumbelliferone for inhibition of hyaluronan synthesis in mice. Clin Exp Immunol 185: 372-381.

Kultti A, Pasonen-Seppanen S, Jauhiainen M, Rilla KJ, Karna R, Pyoria E, Tammi RH, Tammi MI (2009) 4-Methylumbelliferone inhibits hyaluronan synthesis by depletion of cellular UDP-glucuronic acid and downregulation of hyaluronan synthase 2 and 3. Exp Cell Res 315: 1914-1923.

Leal J, Luengo-Fernandez R, Sullivan R, Witjes JA (2016) Economic burden of bladder cancer across the European Union. Eur Urol 69: 438-447.

Lokeshwar VB, Cerwinka WH, Isoyama T, Lokeshwar BL (2005a) HYAL1 hyaluronidase in prostate cancer: a tumor promoter and suppressor. Cancer Res 65: 7782-7789.
Lokeshwar VB, Cerwinka WH, Lokeshwar BL (2005b) HYAL1 hyaluronidase: a molecular determinant of bladder tumor growth and invasion. Cancer Res 65: 2243-2250.

Lokeshwar VB, Estrella V, Lopez L, Kramer M, Gomez P, Soloway MS, Lokeshwar BL (2006) HYAL1-v1, an alternatively spliced variant of HYAL1 hyaluronidase: a negative regulator of bladder cancer. Cancer Res 66: 11219-11227.

Lokeshwar VB, Lopez LE, Munoz D, Chi A, Shirodkar SP, Lokeshwar SD, Escudero DO, Dhir N, Altman N (2010) Antitumor activity of hyaluronic acid synthesis inhibitor 4-methylumbelliferone in prostate cancer cells. Cancer Res 70: 2613-2623.

Lokeshwar VB, Obek C, Pham HT, Wei D, Young MJ, Duncan RC, Soloway MS, Block NL (2000) Urinary hyaluronic acid and hyaluronidase: markers for bladder cancer detection and evaluation of grade. J Urol 163: 348-356.

Lokeshwar VB, Obek C, Soloway MS, Block NL (1997) Tumor-associated hyaluronic acid: a new sensitive and specific urine marker for bladder cancer. Cancer Res 57: 773-777.

Lokeshwar VB, Rubinowicz D, Schroeder GL, Forgacs E, Minna JD, Block NL, Nadji M, Lokeshwar BL (2001) Stromal and epithelial expression of tumor markers hyaluronic acid and HYAL1 hyaluronidase in prostate cancer. J Biol Chem 276: 11922-11932.

Lokeshwar VB, Schroeder GL, Selzer MG, Hautmann SH, Posey JT, Duncan RC, Watson R, Rose L, Markowitz S, Soloway MS (2002) Bladder tumor markers for monitoring recurrence and screening comparison of hyaluronic acid-hyaluronidase and BTA-Stat tests. Cancer 95: 61-72.

McAtee CO, Barycki JJ, Simpson MA (2014) Emerging roles for hyaluronidase in cancer metastasis and therapy. Adv Cancer Res 123: 1-34.

Nagase H, Kudo D, Suto A, Yoshida E, Suto S, Negishi M, Kakizaki I, Hakamada K (2016) 4-Methylumbelliferone suppresses hyaluronan synthesis and tumor progression in SCID mice intra-abdominally inoculated with pancreatic cancer cells. Pancreas 46: 190-197.

Nagata M, Muto S, Horie S (2016) Molecular biomarkers in bladder cancer: novel potential indicators of prognosis and treatment outcomes. Dis Markers 2016: 8205836.

Nakamura T, Funahashi M, Takagaki K, Munakata H, Tanaka K, Saito Y, Endo M (1997) Effect of 4-methylumbelliferone on cell-free synthesis of hyaluronic acid. Biochem Mol Biol Int 43: 263-268.

Pagliaro LC, Keyhani A, Liu B, Perrotte P, Wilson D, Dinney CP (2003) Adenoviral p53 gene transfer in human bladder cancer cell lines: cytotoxicity and synergy with cisplatin. Urol Oncol 21: 456-462.

Peng C, Wallwiener M, Rudolph A, Cuk K, Eilber U, Celik M, Modugno C, Trumpp A, Heil J, Marme F, Madhavan D, Nees J, Riethdorf S, Schott S, Sohn C, Pantel K, Schneeweiss A, Chang-Claude J, Yang R, Burwinkel B (2016) Plasma hyaluronic acid level as a prognostic and monitoring marker of metastatic breast cancer. Int J Cancer 138: 2499-2509.

Piccioni F, Malvicini M, Garcia MG, Rodriguez A, Atorrasagasti C, Kippes N, Piedra Buena IT, Rizzo MM, Bayo J, Aquino J, Viola M, Passi A, Alaniz L, Mazzolini G (2012) Antitumor effects of hyaluronic acid inhibitor 4methylumbelliferone in an orthotopic hepatocellular carcinoma model in mice. Glycobiology 22: 400-410.

Pinto-Leite R, Carreira I, Melo J, Ferreira SI, Ribeiro I, Ferreira J, Filipe M, Bernardo C, Arantes-Rodrigues R, Oliveira P, Santos L (2014) Genomic characterization of three urinary bladder cancer cell lines: understanding genomic types of urinary bladder cancer. Tumour Biol 35 : 4599-4617.

Posey JT, Soloway MS, Ekici S, Sofer M, Civantos F, Duncan RC, Lokeshwar VB (2003) Evaluation of the prognostic potential of hyaluronic acid and hyaluronidase (HYAL1) for prostate cancer. Cancer Res 63: 2638-2644.

Ross RL, McPherson HR, Kettlewell L, Shnyder SD, Hurst CD, Alder O, Knowles MA (2016) PIK3CA dependence and sensitivity to therapeutic targeting in urothelial carcinoma. BMC Cancer 16: 553.

Saito T, Dai T, Asano R (2013) The hyaluronan synthesis inhibitor 4-methylumbelliferone exhibits antitumor effects against mesenchymal-like canine mammary tumor cells. Oncol Lett 5: 1068-1074.

Schmitz-Drager BJ, Droller M, Lokeshwar VB, Lotan Y, Hudson MA, van Rhijn BW, Marberger MJ, Fradet Y, Hemstreet GP, Malmstrom PU, Ogawa O, Karakiewicz PI, Shariat SF (2015) Molecular markers for bladder cancer screening, early diagnosis, and surveillance: the WHO/ ICUD consensus. Urol Int 94: 1-24.

Singh R, Ansari JA, Maurya N, Mandhani A, Agrawal V, Garg M (2016) Epithelial-to-mesenchymal transition and its correlation with clinicopathologic features in patients with urothelial carcinoma of the bladder. Clin Genitourin Cancer 15: e187-e197. 
Takahashi-Yanaga F (2013) Activator or inhibitor? GSK-3 as a new drug target. Biochem Pharmacol 86: 191-199.

Turley EA, Wood DK, McCarthy JB (2016) Carcinoma cell hyaluronan as a 'portable' cancerized prometastatic microenvironment. Cancer Res 76: 2507-2512.

Xu H, Tian Y, Yuan X, Wu H, Liu Q, Pestell RG, Wu K (2015a) The role of CD44 in epithelial-mesenchymal transition and cancer development. Onco Targets Ther 8: 3783-3792.

Xu W, Yang Z, Lu N (2015b) A new role for the PI3K/Akt signaling pathway in the epithelial-mesenchymal transition. Cell Adh Migr 9: 317-324.

Yates TJ, Knapp J, Gosalbez M, Lokeshwar SD, Gomez CS, Benitez A, Ekwenna OO, Young EE, Manoharan M, Lokeshwar VB (2013) C-X-C chemokine receptor 7: a functionally associated molecular marker for bladder cancer. Cancer 119: 61-71.

Yates TJ, Lopez LE, Lokeshwar SD, Ortiz N, Kallifatidis G, Jordan A, Hoye K, Altman N, Lokeshwar VB (2015) Dietary supplement 4-methylumbelliferone: an effective chemopreventive and therapeutic agent for prostate cancer. J Natl Cancer Inst 107: doi:10.93/jnci/djv085.

This work is published under the standard license to publish agreement. After 12 months the work will become freely available and the license terms will switch to a Creative Commons AttributionNonCommercial-Share Alike 4.0 Unported License.

Supplementary Information accompanies this paper on British Journal of Cancer website (http://www.nature.com/bjc) 